\title{
A CONSTRUÇÃO DO ESCRITOR JOÃO ANTÔNIO
}

\author{
The construction of the writer João Antônio \\ La construcción del escritor João Antônio
}

VANIUCHA DE MORAES

http://dx.doi.org/10.1590/S2178-14942017000300009

Vaniucha de Moraes é mestre em Jornalismo e doutorando em Sociologia Política na Universidade Federal de Santa Catarina (UFSC). Este artigo recebeu apoio do Conselho Nacional de Desenvolvimento Científico e Tecnológico (CNPq) (ucha8@ outlook.com).

Artigo recebido em 31 de maio e aprovado para publicação em 30 de agosto de 2017. 


\title{
RESUMO
}

A "persona" do escritor e jornalista João Antônio resulta de um processo de construção social. Trato aqui da edificação de sua imagem em três momentos. No primeiro, abordo a socialização primária e secundária em sua obra. No tocante à socialização primária considero as referências do ambiente familiar, e com relação à socialização secundária analiso as influências do ambiente profissional. No segundo momento, discorro sobre a construção do "nome próprio" do escritor nos mercados profissionais literário e jornalístico entre 1960 e 1990. Por fim, descrevo a continuidade da construção de sua imagem após a institucionalização de seu arquivo pessoal.

PalaVras-CHAVE: João Antônio; literatura; jornalismo; elites; arquivos pessoais.

\begin{abstract}
The "persona" of the writer and journalist João Antônio results from a social construction process. I present here the formation of the writer's image at three moments. At the first one I expose the primary and secondary socialization in the writer's work. Regarding the primary socialization I consider references to the family environment, and regarding the secondary one I analyze the influences of the professional environment. At the second moment, I discuss the construction of the writer's "proper name" in the literary and journalistic professional markets between 1960 and 1990. Finally, I describe the continuity of the construction of the writer's image after the institutionalization of his personal archive.
\end{abstract}

KeYwORDS: João Antônio; literature; journalism; elites; personal archives.

\section{RESUMEN}

La "persona" del escritor e periodista João Antônio es el resultado de um proceso de construcción social. Trabajo la edificación de la imagen del escritor em tres momentos. En el primero abordo la socialización primaria y secundaria en su obra. Sobre la socialización primaria, considero referencias del ambiente familiar y, en relación a la socialialización secundaria, analizo las influencias del ambiente profesional. En un segundo momento trabajo la construcción del "nombre propio" del escritor en los mercados profesionales literario e periodístico, entre 1960 y 1990. Finalmente describo la continuidad de la construcción de la imagen del escritor posteriormente a la institucionalización de su archivo personal.

Palabras Clave: João Antônio; literatura; periodismo; elites; archivos personales. 


\title{
"Sobre o meu nome se poderão ouvir as melhores e as piores coisas. Jamais acreditem." JOÃO ANTÔNIO
}

\begin{abstract}
A produção cultural brasileira atravessou intensas mudanças a partir da segunda metade do século XX, e essas mudanças se evidenciam na construção das carreiras dos membros da elite artística e intelectual. Esta é a premissa que sustenta a presente reflexão, centrada na figura do escritor e jornalista João Antônio, cuja carreira se desenvolveu entre o início da década de 1960 e final da década de 1990. Ou seja: o percurso de edificação de seu "nome próprio" ilustra as transformações ocorridas no mercado profissional jornalístico e literário desde as primeiras publicações de seus contos em jornais e revistas, passando pelo ostracismo até o estabelecimento do Acervo João Antônio.
\end{abstract}

Neste artigo objetivo abordar tais transformações por uma perspectiva que envolve a construção da imagem pública de João Antônio. Assim, parto do pressuposto de que o que se conhece sobre o escritor e jornalista foi paulatinamente construído, primeiramente com sua anuência e relativo controle, e posteriormente por produtores (artistas e acadêmicos) que se debruçaram sobre seus registros. A presente análise se apoia na discussão sobre a origem e a trajetória social de João Antônio e suas relações com as transformações na estrutura social e no campo cultural no intervalo em que ocorreu o processo de profissionalização e autonomização relativa das esferas de atividade nas quais atuou, e também no período em que ascendeu como jornalista e escritor reconhecido no mercado da produção cultural. Abordarei as implicações dessas mudanças em sua trajetória exemplificando-as pela filiação do escritor a uma temática e um gênero textual, respectivamente o tema da marginalidade social e 0 gênero conto (Pontes, 2003: 34).

A fim de analisar a trajetória de João Antônio irei contemplar as diversas experiências de socialização nas esferas sociais em que esteve, para compreender como processou essas referências e as refletiu em sua obra (Lahire, 2015: 1393). Sua trajetória demonstra como impregnou sua literatura com as experiências de socialização em contextos sociais múltiplos e heterogêneos. Elementos de sua obra e de seu percurso também expõem como reteve referências das socializações secundárias obtidas no mercado literário e jornalístico nos quais se 
profissionalizou (Lahire, 2002: 34). A socialização nas esferas de atividade citadas repercutiu em seus contos e reportagens, nos quais se pode entrever os conflitos internos em torno dos princípios de afirmação e hierarquização, e as lutas pelo monopólio da representação legítima do escritor e do jornalista.

O emprego do modelo de figuração estabelecidos-outsiders preconizado por Norbert Elias é certamente eficiente para analisar a trajetória social de um escritor de origem social humilde que ascendeu na carreira tendo a marginalidade como temática central de sua literatura (1995: 22). Isso ocorre porque, em seu percurso, João Antônio experimentou toda sorte de tensões decorrentes das interrelações entre autores consagrados (estabelecidos) e autores de vanguarda (outsiders), podendo-se dizer que esteve em ambas as posições em momentos diferentes. Por isso mesmo, sua vida e obra são significativas para compreender as transformações na literatura e no jornalismo ocorridas a partir da segunda metade do século XX.

Tratarei de três momentos da construção do escritor João Antônio. Primeiramente abordarei a construção social no meio familiar no qual ocorreu a socialização primária, e posteriormente tratarei da construção social via socializações secundárias, resultado das experiências vividas nos ambientes profissionais nos quais foi constituída a identidade do escritor e jornalista. Por fim, abordarei um terceiro momento, em que a construção do escritor perpassa o agenciamento de seu legado e se concretiza na institucionalização de seu acervo e nos trabalhos de pesquisa científicos e artísticos que se originaram de estudos de seu arquivo pessoal. Nesses momentos construtivos da "persona" de João Antônio são empregados diferentes dispositivos. Se, por um lado, é necessário considerar o uso individual do arquivo para fins autobiográficos feito pelo próprio João Antônio, por outro, há o agenciamento social de seus registros por parte de artistas, pesquisadores e responsáveis pelo gerenciamento de seu patrimônio. Entretanto, nos três momentos de análise procuro contemplar o processo deliberado de seleção da informação que compôs e ainda continua a compor a ideia que costumeiramente se projeta a respeito do escritor.

Com a intenção de consolidar uma base consistente para minha argumentação realizei uma pesquisa empírica no Acervo João Antônio que se encontra desde 1998 no Centro de Documentação e Apoio à Pesquisa (CEDAP) da Faculdade de Ciências e Letras da Universidade Estadual Paulista Júlio Mesquita Filho (Unesp), em Assis, São Paulo. Além disso, consultei a biografia Paixão de João Antônio, publicada em 2005 por Mylton Severiano, colega e confidente com quem o escritor manteve um diálogo epistolar. Também analisei textos de autoria de João Antônio, incluindo suas produções jornalísticas e literárias, bem como sua fortuna crítica, constituída por críticas literárias e trabalhos científicos que tiveram o escritor e seus escritos como objeto e fonte de pesquisa, respectivamente. 


\section{ANOS DE FORMAÇÃO}

J oão Antônio Ferreira Filho nasceu em Osasco, região da Grande São Paulo, no bairro Presidente Altino, em 27 de janeiro do ano de 1937, filho de João Antônio Ferreira, emigrante português, e de Irene Gomes Ferreira, carioca que partiu com a família do Rio de Janeiro e se instalou na capital paulista em busca de melhores oportunidades. Sobre a mãe, a biografia do escritor conta que era neta de escravos africanos e de portugueses emigrados da llha da Madeira (Severiano, 2005: 131) e também que era semianalfabeta, fato que impulsionou a dedicação à educação dos filhos. Em contraste com a origem social da mãe, consta que o pai foi alfabetizado na França, pois sua família, originária da região de Trás-os-Montes, em Portugal, mudou-se para o país vizinho a fim de encontrar melhores condições de trabalho. Assim sendo, João Antônio pai recebeu até os 10 anos de idade uma boa educação em escolas públicas francesas e chegou ao Brasil em 1923 tendo como língua materna o francês. Porém no Brasil, em função das dificuldades econômicas e de adaptação ao sistema escolar local, aos 12 anos começou a trabalhar e desse modo aprendeu a ler e a escrever português autodidaticamente. Ao longo da vida, foi garçom e funcionário da contabilidade de um frigorífico até tornar-se dono de um armazém.

0 pai de João Antônio também cultivava hábitos artísticos. Além de leitor autodidata, aprendeu sozinho a tocar violão e bandolim. 0 gosto pela música popular brasileira fez com que se aproximasse de grupos de choro que se reuniam e se apresentavam em várias cidades vizinhas. Nessas viagens, quem o acompanhava era o primogênito João Antônio, a despeito da contrariedade da mãe. Foi a partir dessas primeiras incursões pela vida noturna que o futuro escritor desenvolveu o gosto pela boemia e por ambientes em que circulavam jogadores de sinuca, malandros, viradores e prostitutas, figuras que em seus contos ganhariam dimensão existencial e poética. Na carreira literária de João Antônio, a postura intransigente ao lado dos indivíduos marginalizados e oprimidos consistiu no ponto forte e também no seu "calcanhar de Aquiles", como veremos adiante. Foi essa posição que o fez despontar precocemente no cenário literário como contista, aos 26 anos, com a obra Malagueta, Perus e Bacanaço, e 0 guindou para um dos mais almejados cargos do jornalismo brasileiro nos anos 1960.

Pode-se dizer que na formação artística de João Antônio a música antecedeu a literatura. 0 jovem também começou a aprender a tocar bandolim de forma autodidata ao acompanhar o pai nas reuniões do grupo de choro. Entretanto, sob a rigorosa vigilância da mãe, que não gostava de ver o filho inserido em círculos boêmios, o menino foi progressivamente abandonando a música e migrando para uma forma de expressão artística que não a desapontasse (Lacerda, 2006) e que possivelmente estivesse mais alinhada com as expectativas da família. 
0 autodidatismo musical foi herdado do pai, bem como o interesse por livros. Tudo leva a crer que João Antônio tinha um capital cultural incorporado no seio familiar por influência paterna, e esse foi um fator determinante na constituição de seu gosto pela literatura e no seu autodidatismo (Bourdieu, 1998). Da leitura de jornais, revistas e histórias em quadrinhos evoluiu para a leitura de autores brasileiros e, em seguida, para os clássicos da literatura universal. 0 exercício da escrita foi simultâneo à publicação de textos em um jornal infanto-juvenil intitulado $O$ Crisol, aos 13 anos. Nesse jornal os jovens autores eram pagos com livros, fator que estimulou a produção no jovem escritor. Nesse período as leituras que mais o marcaram foram as obras de Monteiro Lobato, Viriato Correia, Jerônimo Coelho e André Gide, o poema Canção do Expedicionário, de Guilherme de Almeida, e o clássico A Vida do Escravo Tartamudo Esopo (Lacerda, 2006).

Enquanto João Antônio crescia, crescia com ele a vontade de se tornar escritor, e por isso passava grande parte de seu tempo lendo. Em um número da revista $O$ Cruzeiro leu um perfil de Graciliano Ramos em primeira pessoa que o impressionou. Daí em diante, pôs-se a ler os livros do autor, Caetés e São Bernardo, entre outros. Depois, partiu para a literatura realista com Émile Zola e Máximo Gorki. Em relatos biográficos o autor associa o universo dos romances realistas à realidade da boemia e da zona do meretrício que começou a atrair seu olhar na juventude. Conta que também apreciava os modernistas brasileiros Mário e Oswald de Andrade. Posteriormente, viria a conhecer a obra de Guimarães Rosa e especialmente a de Lima Barreto, autor cuja influência foi decisiva em sua literatura (Lacerda, 2006).

Assim sendo, a inclinação para a escrita fez com que João Antônio começasse a ensaiar os primeiros passos em direção à profissionalização, e estes seriam a participação em concursos e a publicação de textos literários em pequenos periódicos. Pode-se inferir que João Antônio ingressou no meio literário com o suporte do jornalismo, que ofertava espaço a tal tipo de publicação, e também que em seu ponto de partida ele ocupava a posição mais baixa na hierarquia dos escritores.

Após concluir o curso normal, João Antônio ingressou no curso de jornalismo da Cásper Líbero e o concluiu algum tempo depois do hiato para servir o Exército. João Antônio certamente não era ingênuo, pois a opção pelo curso de jornalismo veio do conhecimento intuitivo a respeito da tradicional forma de profissionalização do escritor no Brasil via imprensa (Miceli, 2001). Já havia começado a investir na publicação de textos em jornais e com isso conseguia alguma remuneração.

Enquanto isso, uma grande transformação acontecia na indústria cultural brasileira. A partir dos anos 1950 a imprensa passou por uma reforma gráfica e editorial, a televisão fez sua entrada na vida nacional e também o ofício de jornalista se tornou menos amador. Além 
disso, houve a implantação de um modus operandi de fazer jornal com o estabelecimento de uma linguagem específica, manuais de redação, e uma diagramação moderna. A partir do ano de 1969, por força de um decreto federal, ${ }^{1}$ a profissão de jornalista tornou-se exclusividade dos portadores do diploma do curso de jornalismo. Tais transformações tiveram repercussão ao longo da carreira de João Antônio. Entretanto, muitas estratégias de profissionalização nos ofícios intelectuais estavam intactas no momento em que ele neles ingressou.

Intuitivamente ou de forma pragmática, o aspirante a escritor lançou mão de uma série de estratégias para se profissionalizar no meio intelectual. 0 envio de contos e poemas para publicação em jornais e revistas não era algo novo para ele, uma vez que tinha debutado "precocemente" no jornal O Crisol. A novidade agora era a publicação remunerada e o significado disso para sua profissionalização. 0 primeiro conto, intitulado Um preso, foi publicado em 1954 após vencer um concurso do jornal O Tempo. Em seguida, vários outros foram publicados: em 1957, o conto intitulado Busca saiu nas páginas da Revista do Globo; em 1958 o conto Índios venceu um concurso e saiu na revista A Cigarra. Ainda em 1958, João Antônio venceu os concursos da Tribuna da Imprensa e da Última Hora. Assim, tornou-se uma figura frequente nos concursos literários, grande parte deles promovidos por jornais e revistas, nos quais o conto era o gênero escolhido para avaliar os concorrentes. É possível conjecturar que as sucessivas premiações o tenham direcionado para a eleição desse gênero em especial, uma vez que a parte mais robusta e reconhecida de sua produção literária consiste em coletâneas de contos. Pode-se supor que a socialização experimentada no mercado literário tenha constituído um habitus, uma disposição internalizada que justificou a opção pelo conto (Bourdieu, 2009).

Outro expediente empregado pelo aspirante a escritor foi o contato com escritores, editores e críticos literários pela via postal. Nas cartas aos destinatários se apresentava como escritor e enviava seus textos. Era um assíduo missivista e teceu uma extensa rede de contatos que incluía nomes de peso na produção cultural, como a escritora e futura diretora do Departamento de Cinema e Educação da Cinemateca Brasileira Illka Brunhilde Laurito, o intelectual Sérgio Milliet, o tradutor e ensaísta Paulo Rónai, o escritor e crítico Mário da Silva Brito, o escritor e jornalista Ricardo Ramos, filho de Graciliano Ramos, entre outros. Nas cartas buscava o diálogo, divulgava seus escritos e reiterava sua condição de escritor em fase de conquista de reconhecimento, como se pode perceber no seguinte trecho da primeira carta enviada à Ilka Laurito em 1 을 de setembro de 1959:

\footnotetext{
${ }^{1}$ Decreto-Lei no 972, promulgado em 17 de outubro de 1969.
} 
Esta carta vem do último subúrbio. Do morro de Presidente Altino, talvez seu desconhecido [... ] Também acontece que sou moço e faço alguma literatura. Se é literatura eu mesmo não sei. 0 fato é que tenho logrado ganhar alguns prêmios e tenho escrito uns troços que alguns escritores de meu convívio, dizem prestar [...] Hoje em dia, dirijo-me pouco, pouco aos concursos, ando publicando contos no Estado de S. Paulo, na Última Hora, quando posso [...] tenho uns quantos amigos literatos e eles me ajudam um bocado. Costumo assinar João Antônio nos meus contos. Foi o Mário da Silva Brito e o Ricardo Ramos quem me puseram na cabeça: meu nome é muito comprido e não haveria cristão que o retesse e guardasse. Bem, fiquei sendo João Antônio [...]

O diálogo epistolar estava permeado por um sentimento de comunhão e pertencimento a um grupo. Por meio das cartas João Antônio divulgou sua arte e tornou-se reconhecido, constituindo relações duradouras com escritores contemporâneos e um relevante montante de capital social (Bourdieu, 1998). Nas cartas ele compartilhava reflexões sobre a vida, a arte, a política e especialmente sobre as dificuldades no mercado editorial, bem como internalizava gradualmente o habitus do meio profissional.

Impressionava os destinatários com contos sobre a metrópole paulista, seus subúrbios, sua gente sofrida e marginalizada. A muitos críticos literários soou como um Antônio de Alcântara Machado repaginado (autor de Brás, Bexiga e Barra Funda) e preencheu uma lacuna da literatura paulista ao ter sua obra associada a uma espécie de regionalismo urbano (Lacerda, 2006). Ao que parece, João Antônio não forçava a associação com Alcântara Machado, mas também não a negava, uma vez que representava uma posição posta no espaço das possíveis oportunidades de engajamento no meio literário (Bourdieu, 2013).

A rede de relações constituída por João Antônio foi providencial quando um revés ocorreu. Em 1960 um incêndio destruiu a casa em que morava em Presidente Altino deixando a família apenas com a roupa do corpo. No incêndio também foram destruídos todos os pertences do escritor, sua máquina de escrever, vários contos e os originais de Malagueta, Perus e Bacanaço. Após a tragédia demorou até que se recompusesse. Foram fundamentais os incentivos de Ilka e de seus padrinhos literários. Mário da Silva Brito foi quem conseguiu um espaço na Biblioteca Mário de Andrade para que reescrevesse o conto. Em carta enviada à amiga em 8 de setembro de 1960, o escritor fala do momento entre a frustração e a euforia:

A profusão de novidades é muito grande [...] recebi carta do amigo Paulo Rónai que se entristeceu com o meu incêndio, mas que o apagou contando-me o incêndio da vida dele: a última guerra [... Paulo Rónai vai publicar "Meninão do Caixote" na revista da Academia Brasileira de Letras [... . Mário da Silva Brito abriu-me novas portas. Décio de Almeida Prado também. Eu vou. Agora, quando a noite começa eu já estou na minha cela. Cela - é a cabina da Biblioteca Municipal. Cabina 21, cela da ressureição de "Malagueta, Perus e Bacanaço" - três vagabundos em 
busca de definição. Como é tranquila a minha cela! Nem cigarros, nem café! Só, lá fora, o relógio do 0 Estado de São Paulo marca a noite. Eu sou um monge na noite da minha cela. Há um silêncio religioso que lembra cá no segundo andar, uma viagem de ficção-científica. Eu monge, faço uma oração nervosa! "Meu Deus: dê fé ao artista que só tem na vida um terninho chacal, muita zonzeira e uma vontade maluca de fazer uma quizumba a que ele chamou "Malagueta, Perus e Bacanaço". Meu Deus, me dá essa colher de chá.

Posteriormente, a lenda que se criou em torno do incêndio e da reescrita de Malagueta, Perus e Bacanaço terminou por recobrir o conto de mística, pois rumores no meio literário espalharam que o conto havia sido reescrito graças à boa memória do contista e à veracidade de seus personagens. No entanto, o texto não estava de todo perdido quando ocorreu o incêndio. 0 hábito de escrever cartas e enviar trechos de suas elaborações fez com que João Antônio pudesse recuperar grande parte. Quanto ao restante do material, muitas cópias foram enviadas para concursos e por isso puderam ser recuperadas (Lacerda, 2006). Posteriormente, o incidente trouxe publicidade à obra. Malagueta, Perus e Bacanaço, primeiro livro, uma coletânea de contos, foi lançado pela Editora Civilização Brasileira em 1963, quando o escritor tinha 26 anos.

A importância desse acontecimento pode ser conferida em seu arquivo pessoal. Entre as correspondências e documentos guardados, consta uma carta enviada a João Antônio do Rio de Janeiro em 9 de julho de 1962 por Ênio Silveira, proprietário da Civilização Brasileira. Na correspondência se estabelece um contrato de publicação de Malagueta, Perus e Bacanaço. 0 conteúdo da carta revela quão profícua foi a rede de contatos tecida por João Antônio, uma vez que a leitura dos originais foi solicitada pelo crítico literário Mário da Silva Brito. Nela também se percebe que havia uma grande expectativa relacionada à obra do estreante, então comparado por Silveira a Antônio de Alcântara Machado, Mário de Andrade e Orígenes Lessa. A Editora Civilização Brasileira seria responsável pela publicação de outros livros de João Antônio e também pela difusão de sua obra, pois estava entre aquelas editoras que detinham maior adesão junto aos intelectuais e artistas. Após a publicação do primeiro livro a satisfação de João Antônio foi imensa. Em correspondência de 12 de outubro de 1962 o escritor devolve um conjunto de cartas escritas por ele e reenviadas a Ilka. Deduz-se que a amiga havia devolvido as cartas ao remetente para auxiliar João Antônio a reescrever o conto perdido no incêndio.

Representam [as cartas] uma espécie multicor e em diferentes papéis, uma espécie de testemunho da minha solidão. Contam, mais do que a minha própria literatura, a minha literatura. A vontade enorme de crescer, a luta que no fundo outra coisa não era que a fuga ao anonimato. Agora, "Malagueta, Perus e Bacanaço" ganhou prêmio, editor, referência e antologia. 
Após a assinatura do contrato de publicação com Ênio Silveira em 1962 a trajetória da obra foi vitoriosa. Com o livro João Antônio conquistou o prêmio Fábio Prado e dois prêmios Jabuti nas categorias Revelação de Autor e Melhor Livro de Contos em 1963. Após a consagração literária, o escritor ascendeu a uma das mais prestigiadas posições no jornalismo da época. Sob influência dos contatos com o dono da Civilização Brasileira Ênio da Silveira e com o crítico literário e ensaísta Mário da Silva Brito, João Antônio mudou-se para o Rio de Janeiro em 1965 para ocupar o cargo de repórter especial do Caderno B do Jornal do Brasil.

\section{A SAGA DO ESCRITOR MALDITO}

origem e a trajetória social de João Antônio têm uma relação intrínseca com sua obra.
a socialização primária vivida no meio familiar humilde, como filho de emigrante e músico autodidata, modelou o espírito engajado e avesso ao status quo característico do escritor. As seguidas socializações secundárias no meio literário e jornalístico fizeram com que adotasse uma concepção particular sobre a atividade do escritor e do jornalista.

Tal orientação de análise implica em reconhecê-lo como "ator plural" e por isso portador de habitus heterogêneos e contraditórios internalizados no transcorrer da pluralidade de experiências vividas em distintas esferas sociais de atuação (Lahire, 2002: 34). Por isso, faz-se necessário revisitar a história da profissionalização do escritor no mercado literário e jornalístico.

Nos anos 1960 João Antônio ingressou na grande imprensa já na condição de escritor reconhecido e premiado. Entre 1965 e 1966 ocupou a posição de repórter especial do caderno de cultura do Jornal do Brasil. A conquista do cargo aconteceu por meio da indicação de um amigo, o escritor e jornalista Esdras Passaes (Lacerda, 2006). Pode-se notar que ele foi capaz de mobilizar diferentes inserções e reconverter recursos provenientes de outras esferas sociais, a saber, oriundas do meio literário e intelectual paulista, em possibilidade de sucesso no jornalismo nacional. Nesse sentido, cumpre destacar que tal espécie de iniciativa é comum no campo jornalístico no que se refere às tradicionais modalidades de seleção, recrutamento e ascensão a cargos e posições (Petrarca, 2008). Uma das estratégias consiste no estabelecimento de uma rede de relações. Nesse quesito a mudança para o Rio de Janeiro e o ingresso no Jornal do Brasil significaram uma otimização de sua rede de contatos. Em carta enviada a Ilka em 12 de outubro de 1962, João Antônio conta sobre a pressão causada pelo convívio com escritores renomados.

[...] O Caderno B do Jornal do Brasil, onde trabalho é tido por todos aqui como a melhor coisa da imprensa carioca. Nele colaboram José Carlos Oliveira, Ely Azevedo, Ziraldo, Fausto Wolff, Rubem Braga... Se, por um lado, é bom aparecer ao lado de todos esses nomes, por outro, há o meu nome a cuidar. Você sabe. 
A partir do momento em que se estabeleceu no Rio de Janeiro, João Antônio amadureceu como artista e intelectual. No período foi se embrenhando cada vez mais na profissão de jornalista. Passou por algumas das principais publicações da época, muitas vezes tendo que se desdobrar entre o Rio de Janeiro e São Paulo. Trabalhou no jornal Última Hora e nas revistas Cláudia, Manchete, Fatos e Fatos e Realidade.

A revista Realidade 2 merece um capítulo à parte na trajetória de João Antônio. Na redação em que trabalhou entre 1966 e 1969, pôde experimentar produções que marcariam sua obra, uma vez que Realidade era uma publicação dedicada à reportagem, formato textual em vias de ser consolidado na historiografia especializada como gênero emblemático do jornalismo. Nessa época, a opção pelo conto se associou à orientação para a reportagem, e então João Antônio desenvolveu o conto-reportagem, gênero híbrido ao qual se dedicou durante a temporada na revista.

Posteriormente, nos anos 2000, quando a obra de João Antônio começou a ser revisitada, o escritor jornalista foi frequentemente lembrado como repórter que realizou reportagens publicadas em Realidade. A qualidade de autor de reportagens antológicas the concedeu maior prestígio em um contexto em que o conflito geracional entre antigos e novos jornalistas cindiu a profissão em dois grupos a partir dos anos 1980 e 90: os jornalistas por vocação e os jornalistas por formação. Ou seja, os formados pela experiência nas redações e aqueles formados nas universidades. Nesse embate os novos jornalistas foram considerados acríticos por aqueles profissionais que haviam enfrentado a censura do período ditatorial. Desdobramentos desse conflito foram sentidos no território da linguagem, pois enquanto a notícia, texto conciso e não autoral, foi destinada aos novatos, a reportagem, texto extenso, literário e autoral, permaneceu reservada àqueles jornalistas detentores de posições mais elevadas na hierarquia. Isto é, a hierarquia no mercado profissional se equiparou à hierarquia dos textos (Bergamo, 2014: 227). A reportagem tornou-se o gênero jornalístico por excelência, tanto no meio profissional jornalístico como na pesquisa acadêmica nos anos 2000. Por isso, quando a obra de João Antônio foi redescoberta por pesquisadores e intelectuais, a reportagem ganhou lugar de destaque.

A experiência na revista Realidade representou para João Antônio o momento em que se desfizeram as fronteiras entre jornalismo e literatura (Lacerda, 2006). A fusão da linguagem jornalística com a expressão literária deu origem à prática de republicar trabalhos originalmente divulgados em jornais e revistas. Um exemplo seria o conto-reportagem Um dia no cais,

\footnotetext{
${ }^{2}$ A revista Realidade foi a primeira publicação mensal de informação geral da Editora Abril. Foi publicada por 10 anos, porém seu auge foram os primeiros, de 1966 a 1968. Era sobretudo uma revista de reportagens e se destacou pelo diferencial na linguagem e na abordagem temática.
} 
que saiu das páginas da edição de novembro de 1968 de Realidade e foi reproduzido no livro Malhação do Judas Carioca (1975).

Após a experiência na revista Realidade, fatores conjunturais interferiram em uma radical mudança que levou João Antônio à imprensa alternativa. 0 primeiro fator foi o progressivo recrudescimento do regime militar, que instituiu a censura aos meios de comunicação e instaurou de vez o conflito entre intelectuais e a ordem político-militar, fato que deu margem ao surgimento dos jornais alternativos. 0 segundo fator foram as mudanças no campo profissional jornalístico, que na época passava por um processo de tecnicização e profissionalização, o que repercutiu no perfil de profissional com o qual João Antônio se identificava.

Durante os anos 1970, a imprensa alternativa ou "nanica" - expressão cunhada por João Antônio - foi bem-vinda ao trabalho do escritor, uma vez que as características desse tipo de imprensa eram a irreverência e o desmanche dos limites entre os gêneros e expressões. Além disso, era um espaço de militância para artistas e intelectuais. João Antônio escreveu para O Pasquim, Bondinho, Extra-Realidade Brasileira, e em meados da década foi editor da revista Livro de Cabeceira do Homem, uma publicação da combativa Editora Civilização Brasileira. Na revista Extra, foi responsável pela antológica edição Malditos Escritores! (1977) vinculada à Coleção Livro Reportagem que levava na essência de sua proposta a relação entre jornalismo e literatura.

Pode-se dizer que os anos 1970 foram os mais produtivos em função da sintonia existente entre o contexto cultural, as disposições do autor e suas tomadas de posição. Nessa década João Antônio escreveu e publicou Leão-de-Chácara (1975), Casa de Loucos (1976), Lambões da Caçarola - trabalhadores do Brasil! (1977) e Ô Copacabana, os dois primeiros e o último pela Civilização Brasileira, e o terceiro pela L\&PM.

Quanto às suas tomadas de posição, João Antônio se afirmou como escritor marginal tanto pela temática como pela linguagem. No decorrer dos anos 1970 trocou várias cartas com outros jornalistas engajados nos jornais alternativos, além de participar de muitos projetos editoriais. A condição de escritor de vanguarda não favorecia a difusão de sua obra para o grande público, mas causava boa impressão na crítica especializada. No ano de 1975 o escritor foi vencedor do Prêmio de ficção da Associação Paulista de Críticos de Arte com o livro Leão-de-Chácara.

Posicionar-se como escritor marginal ou maldito incluía também associar várias vezes seu nome ao do escritor Lima Barreto, a quem dedicou grande parte de seus livros, a começar por uma reedição de Malagueta, Perus e Bacanaço na qual se pode ler a dedicatória: "Para Afonso Henrique de Lima Barreto, pioneiro, Paulo Rónai, Mário da Silva Brito e Daniel Pedro de Andrade Ferreira - meu filho" (João Antônio, 2004: 21). A dedicatória lembra o filho, os padrinhos Rónai e Brito, escritores e jornalistas que o ajudaram no início da carreira literária, 
e Lima Barreto, a quem qualifica como "pioneiro". Pode-se conjecturar que João Antônio creditava a si mesmo o papel de herdeiro do legado de Lima Barreto. A afeição pelo escritor carioca o levou a produzir um romance histórico-biográfico, Calvário e Porres do Pingente Afonso Henrique de Lima Barreto, lançado em 1974 pela Editora Civilização Brasileira. Em comum, Lima Barreto e João Antônio compartilhavam a posição de escritores malditos em suas respectivas épocas. Ao redigir um romance biográfico sobre Lima Barreto, João Antônio realiza ao mesmo tempo dois feitos importantes: reitera o prestígio do seu ídolo literário e enlaça sua trajetória intelectual à do escritor carioca (Miceli, 2009). Documentos de seu arquivo pessoal demonstram que a respeito de Lima Barreto deu várias palestras em escolas e universidades, produziu reportagens especiais e concedeu entrevistas, ${ }^{3}$ além de produzir um roteiro para uma peça teatral nunca encenada que se chamaria Lima Barreto, anjo maldito. Em 2005, quando Mylton Severiano escreveu a biografia do amigo intitulada Paixão de João Antônio, o vínculo entre João Antônio e Lima Barreto foi reiterado: "de Lima Barreto, tinha a pegada, a postura ao lado dos humilhados e ofendidos" (Severiano, 2005: 59). Pode-se acrescentar que a biografia do escritor paulistano também consagra o nome de Severiano à medida que conjuga as duas trajetórias intelectuais no registro histórico da produção cultural nacional.

Nos anos 1980, contudo, houve um declínio do modelo de jornalista identificado com a militância e a literatura. Profissionalizavam-se o escritor e o jornalista concomitantemente. Aliado a esse fator, outra contingência: o desgaste do discurso da arte engajada. Em determinado momento da literatura brasileira, a temática do jornalista escritor deixou de ter 0 espaço e a importância que tinha, e o tratamento reservado aos seus tipos preferidos, como 0 malandro, a prostituta, o marginal, se enfraqueceu.

Não obstante, na década de 1980 o escritor maldito João Antônio publicou Dedo Duro (1982), Guardador (1986) e Abraçado ao meu rancor (1986). Viajou para várias cidades do país divulgando suas obras; passou temporadas em países como Alemanha e Holanda, e seus livros foram publicados em idiomas estrangeiros. Contudo, a falta de reconhecimento no Brasil foi sentida. Em carta enviada a Mylton Severiano em 28 de maio de 1993, João Antônio declara que, enquanto era reconhecido em outros países, era "marginalizado" no seu próprio país (João Antônio apud Severiano, 2005: 215). 0 escritor paulista antevia os próximos momentos de sua carreira, pois na década de 1990 ele era um escritor quase esquecido pela mídia. Sua derrocada foi resultado de uma conjunção de fatores dos quais os reveses da conjuntura cultural e política apenas fizeram parte. Um dos fatores foi a profissionalização do jornalista e do

\footnotetext{
3 "Recordações de um mulato genial", Revista Isto é, 3/05/1981 pp. 42-47; "Lima Barreto novamente em alta na república dos sonhos perdidos", Jornal da Tarde 3/07/1991 (fragmentos e recortes do Acervo João Antônio).
} 
escritor. Em determinado momento de sua carreira, ao fundir sua literatura com o jornalismo, ele não contava que a profissão de jornalista estivesse gradualmente se autonomizando da literatura e da militância. Quando essa relativa autonomia se efetivou, a obra de João Antônio perdeu a relevância no mercado editorial, uma vez que seu distintivo era a mistura inextricável entre expressão literária e jornalística.

0 caso de João Antônio, um escritor que transitou entre as condições de estabelecido e de outsider, é exemplar para se compreender as dinâmicas do mercado profissional dos produtores culturais brasileiros no período. Nesse sentido, pode-se deduzir que, mesmo sendo na maior parte de seu percurso um escritor marginal e outsider, João Antônio era vinculado ao e dependente do establishment literário. Uma evidência dessa dependência é o seu ressentimento pela falta de reconhecimento em seu próprio país (Elias, 1995: 24), uma sensação tão profunda que inclusive deu título a um dos seus últimos trabalhos, Abraçado ao meu rancor, de 1986.

\section{O LEGADO DE JOÃO ANTÔNIO}

E

m 31 de outubro de 1996 João Antônio foi encontrado morto no apartamento onde morava. De acordo com a apuração da época, o falecimento teria ocorrido pelo menos 20 dias antes, o que chamou a atenção dos moradores do prédio e os levou a chamar a polícia. Apesar da secretária eletrônica cheia de recados não lidos e da pilha de cartas acumuladas embaixo da porta, os anos 1990 são considerados por críticos e estudiosos como um ano de ostracismo para o escritor paulista. Estava cada vez mais afastado da família e da vida social. A opção feita muitos anos antes, de se dedicar apenas à literatura, o levara ao isolamento e ao aprofundamento do alcoolismo.

No entanto, seria forçado dizer que João Antônio morreu inglório e esquecido por completo. Sua morte foi noticiada em jornais e revistas de circulação nacional como 0 Globo, Folha de S. Paulo, O Estado de S. Paulo, Isto é e Caros Amigos. O sepultamento se deu com honras municipais. Naquela década o escritor publicou os livros Zicartola e que tudo vá pro inferno, Dama do Encantado, Patuléia: gente de rua. Além disso, o livro Guardador recebeu o prêmio Jabuti em 1993. A presunção da indiferença da crítica literária e da mídia em relação ao escritor era provavelmente uma consequência da desilusão do próprio em relação às suas contradições em vista da posição que ocupava enquanto intelectual porta-voz dos marginalizados e escritor da classe média que tanto criticava (João Antônio, 1986). Outro fato que lhe provocava descontentamento eram as mudanças na profissão de jornalista. Tal sentimento foi esboçado em um trecho de um dos contos em que João Antônio soou mais autobiográfico. Abraçado ao meu rancor é a confissão do desencanto de um jornalista diante da profissão. 
Esta profissão não presta. Com o tempo, você vai empurrando a coisa com a barriga, meio pesadão. Sem qualquer alegria, garra ou crença, cutucado pela necessidade de sobrevivência apenas. 0 pior, se existe um, é que esta ocupação sovina e instável acaba como que atraindo azares, vícios, mortificações e levantando desejos de destruição, pespegando sentimentos culposos [... ] Com honestidade, garra e jeito vivo, a profissão seria magnífica. Linda (João Antônio, 1986: 81).

Na década de 1990, a consagração de João Antônio aconteceu sobretudo nas universidades, junto aos pesquisadores, ao contrário do reconhecimento alcançado nos anos 1960, momento de sua estreia, e nos anos 1970 na imprensa alternativa. Havia tempo o escritor dava palestras, participava de eventos acadêmicos e fazia sua rede de contatos no meio universitário.

Dois anos após o seu falecimento, objetos e documentos de seu arquivo pessoal foram institucionalizados, constituindo o Acervo João Antônio. No que se refere ao registro de procedência, é mencionada em documentos do Fundo João Antônio a complexidade do trajeto percorrido pelo arquivo, do apartamento em que o escritor vivia no bairro de Copacabana, Rio de Janeiro, até sua chegada ao CEDAP/Campus Assis da Unesp, em função das condições em que ocorreu sua morte em 1996. Seus pertences foram levados a um sítio em Jacarepaguá de propriedade de um primo de sua ex-esposa, Marília Mendonça Andrade, e lá permaneceram precariamente em caixas de papelão de forma desordenada, sem qualquer cuidado de preservação. A Professora Doutora Tânia Celestino de Macedo, que conhecia e matinha contato via cartas com João Antônio, entrou em contato com família do escritor em 1998. Após negociação com Marília e com o filho Daniel Pedro de Andrade Ferreira, herdeiro legítimo do espólio, o fundo foi cedido à Unesp por um prazo inicial de 10 anos. Em seguida começaram os trabalhos de organização e higienização encabeçados pelos docentes Tânia Celestino de Macedo, João Luiz Cardoso Tápias Ceccantini e Ana Maria Domingues de Oliveira (GUIA CEDAP, 2014: 33).

Quando os pesquisadores entraram em contato com o arquivo pessoal de João Antônio, se depararam com as especificidades do conjunto de documentos e objetos, a saber, a subjetividade, a intencionalidade, a seletividade e a arbitrariedade (Nedel, 2010: 145; Heymann, 2009: 50), pois tais documentos são resultado de "um processo de acumulação construído no plano da descontinuidade do tempo, contextos e intenções" (Nedel, 2014: 140). Por causa disso, ao lidar com arquivos pessoais faz-se necessário considerar o contexto de produção dos documentos e de sua acumulação, o que está intrinsecamente associado à investigação da intencionalidade ou dos motivos de guarda, marca registrada dessa modalidade de arquivo (Heymann, 2009: 50).

Quanto às especificidades do arquivo pessoal de João Antônio, pode-se destacar, de acordo com o histórico arquivístico, que o fundo é formado por documentos acumulados pelo escritor no período de 1937 a 1996, e compreende sua produção intelectual, textos datilografados, manuscritos de originais, cartas, discos, revistas, jornais, recortes de textos jornalísticos 
e sua biblioteca particular. Interessa enfatizar que os livros possuem marcas de leitura e dedicatórias de grandes nomes da literatura brasileira, como Jorge Amado, Clarice Lispector, Lígia Fagundes Telles, Raduan Nassar, entre outros. É grande o volume de cartas cujo conjunto de remetentes mapeia o cenário cultural latino-americano das décadas de 1960 a 1990, fornece informações sobre os missivistas e registra a relação entre eles. Desse modo, pode-se mensurar a rede de contatos do escritor e seu prestígio junto aos pares. Tem-se correspondências de escritores como Antonio Candido, Carlos Drummond de Andrade, Cassiano Nunes, Eduardo Galeano, entre outros. Há uma coleção com 383 discos, em sua maioria de música brasileira, uma hemeroteca com jornais e revistas, e móveis oriundos de sua residência.

Porém o conjunto mais revelador a respeito da personalidade do João Antônio consiste na coleção de seus recortes de tudo o que foi publicado a seu respeito em jornais e revistas, seja na condição de autor de contos ou de matérias jornalísticas, seja como assunto das produções (GUIA CEDAP, 2014:32). Graças a essa idiossincrasia de sua personalidade, de ser um colecionador compulsivo e disciplinado de tudo o que saía sobre ele próprio na mídia, o acervo conserva informações preciosas sobre sua trajetória e as repercussões de sua obra no cenário cultural entre as décadas de 1950 a 1990. Portanto, o acervo João Antônio conserva a fortuna crítica do escritor e expõe a intencionalidade de moldar uma determinada imagem de si destinada à posteridade. Essa característica pessoal deixa entrever, ainda, a importância que João Antônio dava ao seu reconhecimento como intelectual e escritor.

Os usos que o próprio titular fez de seu arquivo podem ser verificados em sua biblioteca pessoal. Na extensa coleção de livros pode-se encontrar vários títulos que resumem sua formação literária. Uma curiosidade na edição de Gabriela, cravo e canela de 1963: o autor autografou "Para o mestre João Antônio, que leve adiante a grandeza de Lima Barreto, seu leitor e amigo. Jorge Amado" (novembro de 1983). Chama a atenção a disparidade das datas, o que significa que a dedicatória não foi feita no lançamento, mas a pedido de João Antônio tempos depois. 0 interesse em construir uma reputação entre os escritores é patente pelo grande número de livros autografados por seus contemporâneos, como Dalton Trevisan, Clarice Lispector, Ignácio de Loyola Brandão e Nélida Piñon.

A deliberação em torno da construção de uma imagem pública está implícita tanto em seus registros autobiográficos quanto nas conformações de seu acervo. Há, portanto, em sua produção literária - especialmente nos contos de natureza autobiográfica - um processo de seleção de acontecimentos e enquadramento que objetivam dar coerência e sentido à trajetória da vida (Bourdieu, 1996). Semelhante deliberação está presente na conformação do Acervo João Antônio, com a diferença de que na primeira situação o escritor era quem controlava a construção de seu "nome próprio" e na segunda, essa tarefa foi transferida para 
aqueles que gerenciam o seu legado. Porém, em ambos os casos, o conjunto de informações não corresponde à trajetória de vida do escritor, especialmente no caso do arquivo pessoal, pois é um equívoco confundir trajetória e arquivo. A assunção de que são coincidentes a trajetória e o arquivo escamoteia o interesse de controlar o legado do titular, uma vez que este representa um investimento para os agentes que atuam sobre ele (Heymann, 2012: 75). Em virtude de tais características, a abordagem propícia para investigar os documentos do arquivo pessoal em questão é a análise das condições de circulação e dos usos do arquivo, uma vez que os conjuntos documentais de natureza pessoal são construções sociais passíveis de sofrer a interferência dos agentes que atuam sobre eles (Nedel, 2014; Heymann, 2012).

No que concerne ao Acervo João Antônio, cumpre destacar que, atualmente, o pesquisador que tem acesso ao arquivo pode conferir algo para além dos objetos e documentos que o escritor destinou à posteridade: pode notar as marcas deixadas pela atuação dos gerenciadores e usuários do arquivo. Após a chegada do arquivo pessoal de João Antônio ao CEDAP, várias pesquisas foram desenvolvidas. Ressalta-se que muitos dos pesquisadores ajudaram na ordenação do fundo dando-Ihe assim uma conformação peculiar. É possível supor que essas pesquisas condicionaram a organização atual do acervo de acordo com seus objetos e objetivos. A maior parte partiu da própria Faculdade de Ciências e Letras da Unesp em Assis, ou seja, foi realizada por pesquisadores que manusearam o arquivo. Em suma, são pesquisas que se concentraram no próprio acervo ${ }^{4}$ ou em partes dele, referentes às correspondências ${ }^{5} \mathrm{e}$ às dedicatórias ${ }^{6}$ presentes nos livros da biblioteca pessoal de João Antônio.

A construção da persona de João Antônio recebeu influência do que foi escrito e divulgado a seu respeito. Isto é, a fortuna crítica do autor auxiliou na composição da imagem difundida sobre ele. Entre as origens dos registros analíticos, dois âmbitos de divulgação e legitimação se destacaram: a imprensa e a universidade. Quanto à imprensa, é possível afirmar que os jornais e as revistas foram meios de divulgação significativos para os trabalhos de João Antônio. Não era raro que seus livros tivessem textos primeiramente veiculados na imprensa, por exemplo. Quando atuou como crítico literário, optava por escrever sobre escritores que sintonizassem com seu estilo, ocasião em que aproveitava para divulgar a própria produção. De acordo com Silva, aquilo que João Antônio escreveu sobre si mesmo influenciou no julgamento da crítica especializada (2009: 115). É importante destacar que a abordagem feita

\footnotetext{
${ }^{4}$ Construindo um lugar na história: o arquivo pessoal de João Antônio (1937-1996) - Dissertação de Mestrado de Thais Jeronimo Svicero, 2012.

${ }^{5}$ Posta restante: um estudo sobre a correspondência do escritor João Antônio-Tese de Doutorado de Telma Maciel da Silva, 2009.

6 "Para João Antônio, pela força aos novos e à literatura": dedicatórias como elementos constituintes de um projeto literário

- Tese de Doutorado de Renata Ribeiro de Moraes, 2014.
} 
pela imprensa foi responsável por cristalizar uma ideia a respeito do escritor e sua produção segundo a qual autor e obra seriam indistintos. 0 próprio João Antônio contribuiu para que fosse retratado muitas vezes como um personagem de suas obras ao afirmar que sua escrita resultava de suas experiências. Em seus relatos, João Antônio não se furtava a reiterar o parentesco com os malandros, prostitutas e viradores presentes em seus contos. Desse modo, convencionou um modelo da interpretação sobre sua obra no qual realidade e ficção se confundem. Posteriormente, tal modelo interpretativo engessou sua produção em uma fórmula e o tornou refém do estigma de escritor marginal (Silva, 2009: 139).

João Antônio procurava exercer influência sobre o que a imprensa divulgava a seu respeito e mantinha uma profícua rede de relações com jornalistas e críticos literários. Pode-se dizer que o escritor estava atento à repercussão de seus trabalhos na grande imprensa e à crítica universitária (Silva, 2009: 17). De acordo com Silva, há na fortuna crítica sobre João Antônio uma distinção quanto à origem das análises feitas sobre a obra do escritor. Assim, enquanto os artigos publicados na grande imprensa se restringem à temática do submundo, as reflexões originárias dos círculos acadêmicos recaem sobre outros aspectos. Martin, que se ateve à melancolia que perpassa a composição dos personagens na literatura de "resistência" de João Antônio (Martin, 2004), e Ferreira, com seu viés analítico, expuseram o teor lírico no tratamento de temas áridos presentes na elaboração estética (Ferreira, 2005). As experimentações linguísticas empreendidas por João Antônio compõem o imagético construído pela academia a seu respeito. Antonio Candido, ao analisar os contos de João Antônio, desmistificou a corrente identificação entre autor e obra e se concentrou na habilidade do contista como criador de uma linguagem.

Não se trata, portanto, de mais um autor que usa o pitoresco, como coisa exterior a si próprio, a fala peculiar dos incultos. Trata-se de um narrador culto que usa a sua cultura para diminuir as distâncias, irmanando a sua voz à dos marginais que povoam a noite cheia de angústia e transgressão, numa cidade documentariamente real, e que no entanto, ganha uma segunda natureza no reino da transfiguração criadora (Candido apud João Antônio, 2004: 11).

A avaliação de Antonio Candido realizada por ocasião da morte do escritor, publicada pela primeira vez no jornal O Estado de S. Paulo e tornada prefácio da reedição de 2004 de Malagueta, Perus e Bacanaço, consolida a consagração do escritor paulista no âmbito da produção acadêmica, bem como demonstra uma mudança no percurso crítico da obra de João Antônio, uma vez que, de escritor festejado na imprensa nos anos 1960 e 70, passou a tema privilegiado por pesquisadores a partir dos anos 1990 e 2000. É provável que essa redescoberta tenha sido auxiliada pela institucionalização de seu arquivo pessoal.

O escritor se empenhava na organização de seus papéis, o que pressupõe a intenção que depositava neles, a saber, a de construir condições para o reconhecimento do lugar que 
considerava seu na literatura brasileira (Svicero, 2012: 86). De fato, a partir da década de 2000, diante da profusão de trabalhos acadêmicos, a obra do escritor paulista foi revisitada, e matérias sobre ele foram publicadas. Obras foram reeditadas e uma biografia foi lançada: Paixão de João Antônio (2005). A conexão entre a pesquisa científica e o mercado editorial na redescoberta do autor se evidencia, por exemplo, pelo fato de Rodrigo Lacerda, autor da tese João Antônio - uma biografia literária, defendida no Departamento de Teoria Literária da USP em 2005, ser um dos responsáveis pela reedição da obra de João Antônio por uma editora sofisticada, a Cosac Naify. As novas edições de Abraçado ao meu rancor (2001), Ô, Copacabana (2001), Leão-de-Chácara (2002), Dedo-duro (2003), Malagueta Perus e Bacanaço (2004) e João Antônio - Contos Reunidos (2012) ganharam inclusive encartes com informações sobre o autor e críticas literárias redigidas por especialistas, incluindo o próprio Rodrigo Lacerda. A intenção latente era apresentar ao público um autor considerado subvalorizado pelo mercado editorial.

Há uma consonância entre a imagem instituída por João Antônio e aquela produzida pelas produções posteriores à sua morte. Elas passam a ideia de um escritor avesso às tradicionais instâncias de consagração. Entretanto, João Antônio ansiava pelo reconhecimento de seus pares e, com exceção de seu extraordinário momento de estreia e a recente redescoberta, de modo geral escreveu para nichos específicos. Portanto, o processo de construção de sua imagem pública foi igualmente restrito a poucos. A trajetória do "nome próprio" de João Antônio começou com seu ingresso no campo literário e foi continuada pela consolidação do Acervo João Antônio. Por meio dos registros autorreferenciais pode-se reconstituir as condições estruturais do mercado cultural brasileiro desde o momento em que João Antônio desponta como escritor na década de 1960 até a organização de seu Acervo Pessoal nos anos 2000 (Miceli, 2001).

Finalmente, cumpre reiterar que as repercussões do Acervo João Antônio são inalcançáveis ao jornalista e escritor já falecido, mas as estratégias de unicidade e coerência dadas à narrativa de história de vida estão presentes tanto nos relatos autobiográficos quanto em seu arquivo pessoal institucionalizado. Considerando o esforço empenhado por João Antônio direcionado à edificação de seu "nome próprio" no transcorrer de sua carreira é possível postular que o estabelecimento do Acervo João Antônio dá continuidade à sua trajetória social.

\section{REFERÊNCIAS BIBLIOGRÁFICAS}

ANTÔNIO, João. Abraçado ao meu rancor. Rio de Janeiro: Editora Guanabara, 1986. 243p.

BERGAMO, Alexandre. A escrita do presente: mudanças no status cultural do jornalismo. In: MICELI, Sérgio \& PONTES, Heloísa (org.). Cultura e sociedade. São Paulo: Edusp, 2014, p. 214-239.

BOURDIEU, Pierre. Razões práticas: sobre a teoria da ação. Campinas: Papirus, 1996. . Escritos de educação. Petrópolis: Editora Vozes, 1998. 
. 0 mercado dos bens simbólicos. In: A economia das trocas simbólicas. São Paulo: Perspectiva, 2013.

CANDIDO, Antonio. Na noite enxovalhada. In: ANTÔNIO, João. Malagueta, Perus e Bacanaço. São Paulo: Cosac Naify, 2004.

ELIAS, Norbert. Mozart, a sociologia de um gênio. Rio de Janeiro: Jorge Zahar, 1995.

GUIA do Acervo do Centro de Documentação e Apoio à Pesquisa Profa. Dra. Anna Maria Martinez Corrêa. 2014. Universidade Estadual Paulista Júlio de Mesquita Filho - UNESP - São Paulo. Disponível em: <http:// www2.assis.unesp.br/cedap/guia_acervo_cedap/\#1>. Acesso em: 17 jan. 2016.

HEYMANN, Luciana. 0 indivíduo fora do lugar. Revista do Arquivo Público Mineiro, Belo Horizonte, n. 2, pp. 40-57, jul-dez. 2009.

. O lugar do arquivo: a construção do legado de Darcy Ribeiro. Rio de Janeiro: Contracapa, 2012.

LACERDA, Rodrigo. João Antônio: uma biografia literária. 2006. 501p (Tese de Doutorado em Teoria Literária e Literatura Comparada apresentada na Faculdade de Filosofia, Letras e Ciências Humanas) USP. São Paulo.

LAHIRE, Bernard. Homem plural - os determinantes da ação. Rio de Janeiro: Editora Vozes, 2002.

. A fabricação social dos indivíduos: quadros, modalidades, tempos e efeitos da socialização. Educação e Pesquisa, São Paulo, v. 41, no especial, pp. 1393-1404, dez 2015. Disponível em: http://www.revistas. usp.br/ep/article/view/109892/108393. Acesso em: 17 abr.2017.

MARTIN, Vima Lia. Exclusão social e composição de personagens na ficção de João Antônio e de Luandino Vieira. Via Atlântica (USP), n. 7, out. 2004. pp.183-190

MICELI, Sérgio. Intelectuais à brasileira. São Paulo: Companhia das Letras, 2001. pp. 345-356.

A elite eclesiástica brasileira: 1890-1930. São Paulo: Companhia das Letras, 2009.

NEDEL, Letícia. Da sala de jantar à sala de consultas: 0 arquivo pessoal de Getúlio Vargas nos embates da história política precoce. In: TRAVANCAS, I; ROUCHOU, J; HEYMANN, L. Arquivos pessoais: reflexões disciplinares e experiências de pesquisa. Rio de Janeiro: FAPERJ/Ed. FGV, 2014, pp.131-164.

. A guardiã da verdade. In: FERREIRA, Marieta de Moraes (org.) Memória e identidade nacional. Rio de Janeiro: Ed. FGV, 2010, pp.125-158.

PEREIRA, Jane Christina. A poesia de Malagueta, Perus e Bacanaço. Patrimônio e Memória (Unesp-FCLAs-CEDAP), v.1, n. 2, 2005, pp. 168-172.

PETRARCA, Fernanda. Elites jornalísticas, recursos políticos e atuação profissional no Rio Grande do Sul. TOMO (UFS), n. 13, 2008.

PONTES, Heloisa. Cidades e intelectuais: os "nova-iorquinos" da Partisan Review e os "paulistas" de Clima entre 1930 e 1950. Revista Brasileira de Ciências Sociais. São Paulo, v. 18, n. 53, outubro 2003, pp. 33-52.

SEVERIANO, Mylton. Paixão de João Antônio. São Paulo: Editora Casa Amarela, 2005.

SILVA, Telma Maciel da. Posta restante: um estudo sobre a correspondência do escritor João Antônio. 2009. 292p. (Tese de Doutorado apresentada à Faculdade de Ciências e Letras de Assis) UNESP. São Paulo.

SVICERO, Thais Jeronimo. Construindo um lugar na história: o arquivo pessoal de JA (1937/1996). 2012. 106p. (Dissertação de Mestrado apresentada à Faculdade de Ciências e Letras de Assis) UNESP. São Paulo. 